\title{
Potência da razão e as limitações do ato humano: ciência é esponsalidade com o Criador
}

\author{
Power of Reason and the Limitations of Human Act: Science Is Spousality \\ with the Creator
}

Odirlei Arcangelo Lovo

RESUMO

\begin{abstract}
A potência da razão e as limitações do ato humano, evidencia a necessidade de planejar, de prever, de expectar e de esperançar o futuro e, neste sentido, ser a ação necessária para realizar, em família, o mundo que se deseja. Essa capacidade de planejar e realizar precisa ser compreendida sob a perspectiva de esponsalidade com o Criador. Quando o ser humano se destoa da esponsalidade se torna demolidores do reino, obcecado por construir a Torre de Babel, fomenta a discórdia e absolutismos. A proposta de narrar o ser humano administrador e cocriador da obra de Deus, embasa-se nos documentos da Doutrina social da Igreja e nos documentos que elucidam a vida e vivência da família 'moral familiar'. Pontua-se sobre as dimensões de sociabilidade, de economicidade e de parentalidade, sustentando ser está a base para que o ser humano administre a obra de Deus. A ciência possibilita a visão global da realidade, mas será uma visão livre e finita, e sem a perspectiva do Reino de Deus, condicionará as pessoas ao individualismo e a desrealização da unidade, em função dos projetos de domínio absoluto.
\end{abstract}

Palavras-chave: Criação. Cuidar. Cultivar. Essência Administrativa. Responsabilidade.

ABSTRACT

The power of reason and the limitations of the human act, shows the need to plan, to predict, to expect and to hope for the future and, in this sense, to be the necessary action to realize, in family, the world that is desired. This ability to plan and carry out needs to be understood from the perspective of responsibility with the Creator. When the human being detaches from the spousality, he becomes the destroyers of the kingdom, obsessed with building the Tower of Babel, foments discord and absolutisms. The proposal to narrate the human being, administrator and co-creator of the work of God, is based on the documents of the social doctrine of the Church and on the documents that elucidate the life and experience of the family 'family morals'. The dimensions of sociability, economics and parenting are pointed out, maintaining that this is the basis for the human being to manage the work of God. Science makes possible a global view of reality, but it will be a free and finite view, and without the perspective of the Kingdom of

1 Professor da universidade Federal de Rondônia. Doutorado em Teologia pela Pontifícia Universidade Católica do Paraná. Contato: oalovo@gmail.com . Submetido em: 08/06/2020; aceito em: 30/12/2020. 
God, it will condition people to individualism and the unrealization of unity, according to projects of absolute domination.

Key-words: Creation. Caring. Cultivate. Administrative Essence. Responsibility.

\section{Introdução}

É preciso aproximar-se das divergências e convergências entre a potência da razão e as limitações dos atos da pessoa. Fala-se de uma realidade administrável, pontua-se que, o ser humano tem a capacidade de promover o amor, no espaço e no tempo onde se desenvolve a história da Criação. Apresenta-se que, são precisamente as limitações entre a razão e o ato humano, que possibilita identidade, mas, ao mesmo tempo, torna a pessoa, profundamente responsável, pelas ações e atitudes. A capacidade humana versa seu propósito na esponsalidade com o Criador; se é, então, o ato de amor dirigido à singularidade de cada espaço e tempo na história humana.

A pesquisa, os esquemas e as indagações objetivaram hipóteses aos pesquisadores fomenta-se narrativas verificáveis e que tem por finalidade expressar a vida humana. Com afirmativas, administrativas e teológicas, desenvolveu-se a pesquisa tendo como 'pano de fundo' a parentalidade, a economicidade e a sociabilidade humana.

É afirmativa a associação e inter-relação, enquanto metodologia, entre Teologia e Administração, de modo que, realizar a vontade de Deus - esponsalidade - significa administrar a criação e, por isso, há práxis teológica e, à medida que se faz teologia, compreende-se como administrar a Criação e, neste sentido, subentende-se que "a vida que Deus oferece ao homem, é um dom, pelo qual Deus participa algo de Si mesmo à sua criatura" (EV 34).

Eis que "lahweh Deus tomou o homem e o colocou no jardim de Éden para o cultivar e o guardar" (Gn 2,15). Sendo dever do ser humano cultivar o jardim, insere-se o momento posterior, a necessidade de administrar e cocriar. Administrar e dar significado, sentido e possibilidades ao que existe, avançando sobre o que não é possibilitado, mas que se alça em ser possibilitado, no futuro, pela ação humana, mediante a essência administrativa.

O humano sempre se des-envolve, mediante a essência administrativa e se torna ato administrativo de Deus na criação. Enseja-se que a esperança é constitutiva da ação necessária em perspectiva do reino esperançado, é preciso compreender que "a interpretação correta do conceito de ser humano como senhor do universo é entendê-lo no sentido de administrador responsável" (LS 116).

Diante do que se apresenta em epigrafe, procurou-se a elucidação de questões que estão relacionadas ao ser humano, vertendo-se a compreendê-lo como administrador da obra de Deus. Mediante os procedimentos metodológicos, conduziu-se às possibilidades, às interpretações e às informações, na afirmativa que "uma narrativa é composta por uma sequência singular de eventos, estados mentais, ocorrências envolvendo seres humanos como personagens ou autores" (BRUNER, 2002, p. 46).

A narrativa tem por finalidade explorar, aprofundar e dar respostas às particularidades, onde a realidade não pode, ou não deve ser quantificada, particularizando ainda que, "Uma verdadeira pesquisa narrativa é um processo dinâmico de viver e contar histórias, e reviver e recontar histórias" (CLANDININ e CONELLY, 2011, p.18).

Para explorar o universo dos significados, das aspirações, das crenças, dos valores e práxis humana, utilizou-se, para a narrativa, dois núcleos fundamentais de dados, textos e informações, a saber: os documentos que constituem a (DSI) - Doutrina Social da Igreja; e os 
documentos que elucidam o projeto, a vivência e a dinâmica familiar, segundo a igreja católica. O uso desses dois núcleos tem por base, sua universalidade, isto é, são documentos que se destinam a toda a humanidade, diante dos dons de cada pessoa.

Cada um dos itens da pesquisa foi desenvolvido, tendo por base os textos/documentos apresentados. Como pontos de discernimento, pesquisou-se fontes/obras para dar às narrativas, sentido de diálogo, com fundamentações de teólogos que não estão inseridos nos dois núcleos apresentados. As obras foram escolhidas pelo próprio pesquisador, tendo como critério a afinidade com o texto, sendo este o critério metodológico para sua escolha.

\section{$O$ ato de quem é imagem e semelhança de Deus}

Deus que fez a Criação do nada - ex-nihilo, criou o ser humano do húmus da criação, no chamado a $\mathrm{Si}$ e no mandado de $\mathrm{Si}$, deseja, por isso, pessoas com identidade, personalidade. Deus quer a pessoa livre, consciente e responsável, na unipluralidade das culturas e, neste sentido, sob as perspectivas de um reino em desenvolvimento "as múltiplas sociedades são chamadas a constituir um tecido unitário e harmônico, onde cada uma possa conservar e desenvolver a própria fisionomia e autonomia" (CDSI 151).

O humano é práxis, uma missão dada a si mesmo e, para tanto, se deve observar que Deus deu um mandado à cada pessoa e, conforme descrito "no Gênesis lembra-se como Deus impôs aos primeiros seres humanos dois mandamentos: o de transmitir a vida: 'Crescei e multiplicai-vos' (Gn 1,28) e o de dominar a natureza: 'Enchei a terra e submetei-a' $(G n, 1,28)$ ” (MM 195).

Quando se enfatiza a essência administrativa no humano, fala-se de que a pessoa, mediante a razão iluminada pela esponsalidade, pode planejar o que vai fazer. A habilidade dos sentidos possibilita abstrair-se do momento, e manter-se na realidade, para visualizar as coisas segundo uma nova lógica, bem como sua relação com o tempo.

A sutileza da razão humana, bem como a limitação do ato humano, torna tácito, visível, sensível e perceptível a divindade e o amor de Deus, segundo a realidade que acontece na vontade de cada pessoa; por isso, "ao exercer a imago Dei, ao pôr em prática nosso caráter de co-criadores, esbarramos no fato de nosso ser-criado" (HEFNER, 1987, p. 329).

Quando se enfatiza o abstrair-se do momento, enseja-se que a realidade seja exponenciada na expectação de vida humana e, assim, elevada a formar o futuro em esponsalidade com o Criador. Todavia, não se pode "prever adequadamente os resultados de nossas mais importantes ações, nem podemos mitigar todas as consequências indesejáveis de nossas decisões e ações livres mas finita" (HEFNER, 1987, p. 329).

Assim, não é que os atos humanos estão dispersos e divergentes da própria racionalidade, mas, que os atos humanos precisam, sempre, ser planejados e administrados, pois eles cocriam e administram a obra de Deus, em família; "trata-se do fato que nosso mandato para co-criar veio a nós enquanto criaturas, por comando do Deus criador ex-nihilo e não de nossa própria vontade autogeradora" (HEFNER, 1987, p. 329).

$O$ ato humano deve ser fruto de profunda reflexão/planejamento, em esponsalidade

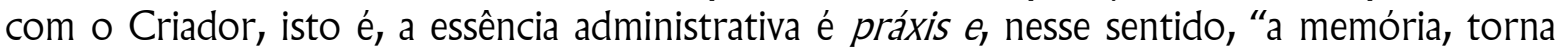
presente o passado e, através da expectativa, torna presente o futuro, proporcionando, assim, uma relativa unidade do tempo" (MOLTMANN, 1993, p. 179). O humano se aventura ao não possibilitado, é participante da criação e quando se propõe a se edificar em sociabilidade, em parentalidade, e em economicidade o faz para reconhecer que caminha a unidade do reino.

É nesta, vida e vivência humana, que a unidade propicia perceber que "a sociabilidade humana não é uniforme, mas assume multíplices expressões" (CDSI 151). É perceptível que, diante da pluriculturalidade, haja a unidade na vontade do Criador, na edificação da grande 
nação do amor ao próximo, e com isso "o bem comum depende, efetivamente, de um são pluralismo social' (CDSI 151).

Lembra-se o dever de "cultivar e guardar o Jardim" (Gn 2,15) e, com isso, há que se dizer que o ser humano deve executar algo na criação de Deus, embora essa práxis a ser executada só aconteça porque Deus possibilita ao ser humano a Graça da essência administrativa, práxis e dom. Com isso, a pessoa torna-se o ato administrativo de Deus no mundo, "Se o próprio criador habita na sua criação, então ele faz dela o seu lugar de se sentir em casa 'assim na terra como no céu"' (MOLTMANN, 1993, p. 22),

Ser co-criador significa que precisamos continuar a viver com a decisão de exercer nosso caráter de co-criadores responsáveis, quer a decisão comprove ser desejável ou indesejável, ou, como é mais provável, tenha tanto consequências indesejáveis quanto desejáveis (HEFNER, 1987, p. 329).

Deus que fez a Criação do nada - ex-nihilo, criou o ser humano do húmus da Criação, no chamado a Si e no mandado de Si, para que houvesse na Criação um ser à sua imagem e semelhança, ou seja, um administrador da obra, "Com efeito, a verdade é 'lógos' que cria 'diá$\operatorname{logos}^{\prime}$ e, consequentemente, comunicação e comunhão" (CiV 4) e, nesse sentido, se insere a esponsalidade, dia-logos de Deus com o ser humano.

A ausência de comunhão e fraternidade humana se faz quando o ser humano na "busca exclusiva do ter, forma então um obstáculo ao crescimento do ser e opõe-se à sua verdadeira grandeza: tanto para as nações como para as pessoas, a avareza é a forma mais evidente do subdesenvolvimento moral" (PP 19). Desenvolver-se, enquanto cocria o Reino, é uma práxis dada a cada pessoa, que edifica a si mesmo em família e humanidade, a ser o templo do Espírito Criador, portanto, Criatura ungida.

\section{A capacidade de planejar e realizar}

Toda pessoa ao administrar a criação, edifica a si mesmo, e assim, quando o ser humano se reconhece amado por Deus "compreende a própria dignidade transcendente, aprende a não se contentar de si e a encontrar o outro, em uma rede de relações cada vez mais autenticamente humanas" (CDSI 4).

A essência administrativa é práxis, é ato de refletir/planejar em esponsalidade com o Criador. O convite ao ser humano para administrar a Criação, submete-o a tomar decisões de forma a desvendar o bem e o mal, em cada uma das situações que o impele a agir na Criação. Sempre houve e haverá distância entre nossa capacidade de diagnosticar/planejar/prever e nossa capacidade de fazer/realizar/esperançar; trata-se, pois, de um reino em desenvolvimento, portanto, contingente.

A mudança/transformação acontece em dimensão estritamente pequena, de modo que se possa alterar o sentir, sem alterar o que gera os sentidos. É evidente que isso denota uma nova lógica por si mesmo, então se diz que após cada ato humano uma nova lógica se faz. $O$ ato humano não é um alterar do Bom, do Belo e do Verdadeiro, mas é um reconstruir das possibilidades na criação e, por consequência, um melhorar a capacidade que o ser humano tem de sentir-se amado por Deus, e "é por isso que tem o direito de escolher as coisas que julgar mais aptas, não só para prover ao presente, mas ainda ao futuro" (RN 5).

Por vezes, apequena-se a capacidade humana de cocriar e administrar a criação, mas é a capacidade de que Deus precisa para que sua obra possa ser concluída, na contingência do reino e do ser humano, para a glorificação de Deus e de todas as criaturas que agem na perspectiva do Reino, 
O homem abrange pela sua inteligência uma infinidade de objetos, e às coisas presentes acrescenta e prende as coisas futuras; além disso, é senhor das suas ações; também sob a direção da lei eterna e sob o governo universal da Providência divina, ele é, de algum modo, para si a sua lei e a sua providência. (RN 5).

É diante da atitude de cada pessoa que o ser humano se põe a administrar e cocriar a obra de Deus, descobrindo os infindáveis mistérios de amor que Ele possibilita a vida humana. No sentido de compreender a plenitude dos tempos, o ser humano movimenta-se em esperanças. Todavia, se em uma semente está sua possibilidade ou não possibilidade, imagine o ser humano como senhor desta semente, ele e só ele poderá conduzi-la a um local onde há possibilidade de se tornar árvore e frutificar.

O que ninguém é capaz de dizer é até que ponto este fim é uma corrida do mundo em direção à morte, de acordo com as leis internas; até que ponto se trata de um parar decretado pela palavra criadora e ordenadora de Deus nem até que ponto finalmente, ambas as coisas se reduzem ao mesmo. (RAHNER, 1969, p. 148),

A pessoa pode gerar a não possibilidade, assim, ela se torna um interceptador da Graça de Deus, com isso torna-se egolátrica, e afasta-se da vontade do Criador, "De qualquer maneira, sabemos pelo testemunho de Deus que essa história do mundo terá fim e que esse fim não será um simples cessar, um deixar de existir do mundo em si, mas a participação na realização do espírito" (RAHNER, 1969, p. 133).

Com o avançar da ciência, a distância entre a potência da razão e as limitações dos atos humanos, parecem diminuir, na realização da práxis mediante as tecnologias desenvolvidas. Apresenta-se que, a misericórdia e a compaixão unem razão e ato, evidenciando o quanto se é administrador e cocriador da obra de Deus.

Porém, quando se nega o senhorio sobre a 'semente', coloca-se novamente a responder a Deus "'Sou porventura, guarda do meu irmão?: Caim não pensa no irmão, e recusa-se a assumir aquela responsabilidade que cada humano tem pelo outro" (EV 8). Pode-se dizer que, ainda há muitos 'Caim', todavia, não é este o propósito para a vida humana.

Deus concebeu o ser humano, no propósito de ser à Sua imagem e semelhança, manterse em esponsalidade com o Criador é ser o ato administrativo de Deus no mundo, isso não é só um zelo com a parentalidade, mas é, na parentalidade que se propicia o espírito de família humana e, desse modo, funda-se a fraternidade dos filhos de Deus, havendo, acima de tudo, nossa responsabilidade para com todas as pessoas, uma vez que todos são concebidos à imagem e semelhança de Deus,

O espírito é o que tem em si impressa a semelhança divina, e no qual reside aquele principado em virtude do qual foi dado ao homem o direito de dominar as criaturas inferiores e de fazer servir à sua utilidade toda a terra e todo o mar: 'Enchei a terra e tornai-vo-la sujeita, dominai sobre os peixes do mar e sobre as aves do céu e sobre todos os animais que se movem sobre a terra' (RN 23).

Vislumbra-se que o livre-arbítrio é constituído na responsabilidade, e que ser semelhante ao Criador é administrar e cocriar o Reino. É necessário enfatizar que o amor aflora na dimensão de sociabilidade humana, e que a parentalidade é fonte de onde jorra sem cessar 
o amor e, ainda que "a vida temporal, posto que boa e desejável, não é o fim para que fomos criados; mas é a via e o meio para aperfeiçoar, com o conhecimento da verdade e com a prática do bem, a vida do espírito" (RN 23).

A potência humana não é para tomar a criação para si, mas para torná-la apta a receber os filhos, possibilitar o nascer, o crescer e o proliferar da 'semente', de forma que se possa ser o ato administrativo e cocriador de Deus na criação. Negar-se à Obra ou desejar possuí-la de forma avarenta, é contrapor-se à essência administrativa, o Si de Deus, que habita o íntimo humano.

\section{Pessoa e Ciência}

O cuidado a toda pessoa, merece ser pensado sob a perspectiva de que a razão é um estágio de humanidade nos humanos, por isso, quando em esponsalidade com o Criador, reflete a consciência de quem deve cuidar e desenvolver a vida humana. Administrar e cocriar a obra de Deus é, então, assumir-se responsável pela vida humana, que se inicia na concepção.

Compreende-se que a concepção e a dignidade da pessoa estão intimamente associadas, por isso, ressoa desde o ventre, a voz de Deus que pergunta sobre nossa responsabilidade para com a vida humana, "Onde está teu irmão?" (Gn 4,9). E, há que se pontuar que, "muitas vezes, justifica-se que se ultrapassem todos os limites, quando se fazem experiências com embriões humanos vivos. Esquece-se que o valor inalienável do ser humano é independente do seu grau de desenvolvimento" (LS 136).

A razão é talento, possibilitado por Deus, e desenvolvido pelo ser humano, para refletirse em elemento de concórdia entre os seres. Ressalta-se que "a atividade humana, do mesmo modo que procede do homem, assim para ele se ordena. De fato, quando age, o homem não transforma apenas as coisas e a sociedade, mas realiza-se a si mesmo" (GS 35), isto é, quando há o cuidado com a vida humana, há o agir na própria vida que é edificada.

Implica dizer que a Graça possibilita compreender a Providência, mas que, entre a Graça e a Providência, é necessário que haja a essência administrativa, e isso faz com que o humano "aprenda muitas coisas, desenvolva as próprias faculdades, saia de si e eleve-se sobre si mesmo" (GS 35). A essência administrativa é práxis, por isso, ao ser humano, é dito: "conforme o dom que cada um recebeu, consagrai-vos ao serviço uns dos outros, como bons dispenseiros da multiforme graça de Deus" (1Pd 4,10). Sem esponsalidade,

O ser humano se declara autônomo da realidade e se constitui dominador absoluto, desmorona-se a própria base da sua existência, porque 'em vez de realizar o seu papel de colaborador de Deus na obra da criação, o homem substitui-se a Deus, e deste modo acaba por provocar a revolta da natureza' (LS 117).

Avançar sobre as coisas não possibilitadas não é um abandonar a Deus, é precisamente fazer a vontade do Criador, e todo aquele que "faz a vontade do Pai" (Jo 6,38) é com Cristo, filho de Deus. Todo o conhecimento perceptivo à corporeidade humana é uma chance de o humano humanizar-se, no relacionamento que acontece entre as pessoas, a criação, e Deus, que se realiza o desenvolvimento do reino.

O desenvolvimento da práxis de vida e vivência humana é "a abertura a um 'tu' capaz de conhecer, amar e dialogar continua a ser a grande nobreza da pessoa" (LS 119), e com isso "o lado da criação aberto para Deus nós designamos de 'céu'. A partir do céu e através dele, Deus atua sobre a terra" (MOLTMANN, 1993, p. 265), de modo que, 
O Povo de Deus, movido pela fé com que acredita ser conduzido pelo Espírito do Senhor, o qual enche o universo, esforça-se por discernir nos acontecimentos, nas exigências e aspirações, em que participa juntamente com os homens de hoje, quais são os verdadeiros sinais da presença ou da vontade de Deus (GS 11).

Quando o humano se põe a desvendar os mistérios da criação, está conhecendo a si mesmo, tendo a oportunidade de doar-se como ato administrativo de Deus na criação. Sob a perspectiva de uma criação em desenvolvimento, há que se observar que a criação (criar+ação/agir) de Deus, inspira algo que aconteceu, e está acontecendo.

O ser humano precisa de toda ciência, com a qual seja capaz de promover o bem à pessoa. Quando se diz toda ciência, há aqui, a consciência de que a ciência não é um mal em si. A ciência é a práxis do agir e do desenvolvimento do ser humano no reino. $O$ conhecimento não define ou classifica a própria ciência, mas, o uso do produto, conhecimento, mediante a ciência é que pode revelar o bem ou o mal.

Deve-se reconhecer que o uso de métodos incorretos pode fazer com que a ciência percorra os caminhos inadequados para a realização do que se deseja saber, mas isso é uma escolha do cientista/pesquisador, da pessoa. O problema não é o saber, mas os meios/métodos pelos quais se deseja chegar ao saber, ou ainda, como se usa o saber. Destaca-se que não é atribuição classificar as ciências entre o fruto proibido e permitido, mas que a função da ciência é verificar o que há de proibido em cada fruto, e isso acontece diante da práxis em esponsalidade com o Criador.

Deus aproxima o ser humano da ciência, e a ciência aproxima o ser humano de Deus, a ciência é o desenvolver-se com Deus; o mau uso da ciência, e do conhecimento por ela gerado, afasta-se da esponsalidade e, com isso, a sedução pelo conhecimento torna-se a ação do indivíduo subvertido de sua função de administrar e cocriar o reino de Deus.

Com efeito, Deus criou os homens sociais por natureza e, já que sociedade alguma pode 'subsistir sem um chefe que, com o mesmo impulso eficaz, encaminhe todos para o fim comum, conclui-se que a comunidade humana tem necessidade de uma autoridade que a governe. Esta, assim como a sociedade, se origina da natureza, e por isso mesmo, vem de Deus' (PT 46).

Quando se fala da essência administrativa, fala-se da capacidade de administrar e de ser administrado, eis que a razão humana permite ser (minor) e se colocar junto de (ad), para que, em sociabilidade, em economicidade e em parentalidade se possa ad-ministrar a Graça de Deus e não interceptá-la ao próximo. A responsabilidade é o sentido administrativo, aguçando-se por unidade, contingente, mas propiciadora do caminho à unidade em Deus.

Dessa forma, é justa a observação de que a autoridade está associada à responsabilidade e, portanto, desenvolve-se a capacidade política, no sentido de se reconhecer e desenvolver as dimensões de sociabilidade, de economicidade e de parentalidade de toda pessoa. $O$ fato de ser governado ou governante, não inibe a relação de alteridade entre as partes, por isso, a unidade é sempre edificada diante do distinto de si, na construção de uma liberdade social e responsável, onde todas as pessoas possam ser administradores e cocriadores.

\section{Ciência: visão global da realidade}

Há sempre uma tensão entre a potência da razão e a limitação do ato humano, é possível afirmar que na estrutura da própria pessoa, “origina-se com frequência um desequilíbrio entre 
o saber prático moderno e o pensar teórico, que não consegue dominar o conjunto dos seus conhecimentos nem ordená-los em sínteses satisfatórias" (GS 8).

A potência humana é sempre dependente da práxis humana, que é erigida para cocriar e administrar o que existe. É, portanto, sempre dependente das coisas criadas por Deus, surgindo, então, o "desequilíbrio entre a preocupação da eficiência prática e as exigências da consciência moral; outras vezes, as condições coletivas da existência e as exigências do pensamento pessoal e até da contemplação" (GS 8).

Diante da egolatria de cada pessoa "gera-se, finalmente, o desequilíbrio entre a especialização da atividade humana e a visão global da realidade" (GS 8). Nesse cenário, apresenta-se que há o desencantamento com a Criação de Deus e uma sistemática atividade, que apequena o projeto de Deus ao desejo idolátrico de cada pessoa.

Nesse sentido, diz-se que os seres humanos "desencaminhados na inteligência ou pervertidos na vontade, se valem desses meios contra a razão, isto é, para fins que não correspondem à sua própria natureza social nem aos planos da Providência" (MM 198). A fraternidade é a plenitude dessa aventura cocriadora humana, que busca participar e ser cocriador e administrador da obra de Deus. A práxis é movimenta cada pessoa, no sentido de evidenciar que se é irmãos, filhos de Deus, segundo o livre-arbítrio, na vida e da vivência humana.

Toda pessoa deve utilizar o conhecimento em esponsalidade, "porque a fé ilumina todas as coisas com uma luz nova, e faz conhecer o desígnio divino acerca da vocação integral do homem e, dessa forma, orienta o espírito para soluções plenamente humanas" (GS 11), sentido em que a ciência humana se faz no propósito da onisciência de Deus e se complementa para a realização e desenvolvimento do reino, na contingência da criação humana. Cada povo/comunidade se desenvolve, segundo os próprios conhecimentos. A esperança possibilita ao ser humano, nunca perder a expectativa de cocriar e a caridade possibilita olhar para toda a família humana com misericórdia.

Quando a ciência humana se faz no propósito da onisciência de Deus, mesmo os povos desenvolvidos, jamais olharão com desprezo todos os que são em Deus seus semelhantes. Quando a ciência humana, tem fins em si mesma, o ser humano destoa da harmonia cocriadora e administradora da criação, e rebela-se contra o reino, porque "A providência de Deus que concede ao gênero humano meios suficientes para resolver dignamente os múltiplos e delicados problemas da transmissão da vida" (MM 198).

A essência administrativa desperta diante da esponsalidade humana com o Criador, é práxis de amor que acontece diante das atitudes humana de administrar e cocriar os mistérios de Deus. A aliança esponsal com o Criador é o que direciona o ser humano aos verbos (Palavra), porque, se o desejo é ver no outro algo do ser, é através dos sentidos corpóreos que se compreende a práxis de vida e vivência humana.

Sob os preceitos de liberdade, de responsabilidade e de ciência é possível enfatizar que "cada consciência é interpelada e convidada a interagir com todas as demais, na liberdade, em plena corresponsabilidade com todos e em relação a todos" (CDSI 163), "a liberdade, assim como a conhecemos agora, é caracterizada por risco, por contingência" (SPONHEIM, 1987, p. 215).

A negação da responsabilidade com próximo é a construção da "torre de Babel" (cf. Gn 11,1-9), em sentido contrário "é uma coisa boa e nobre conhecer Deus como fundamento da vida, pois, conhecendo isto, conhece-se a dádiva da liberdade e seu elemento concomitante, a responsabilidade" (SPONHEIM, 1987, p. 215).

A comunicação é o que exprime o desejo de saber/ensinar, é pela palavra que o ser humano se conhece, "e os teólogos estão nos conclamando a um novo diálogo com as religiões universais. Por isso, é urgente que saibamos o que queremos dizer com a unicidade e universalidade de Jesus Cristo" (BRAATEN, 1987, p. 546). Percebe-se, diante da contingência 
dos atos humanos, ao mesmo tempo, que se está em íntima relação com o Criador. A esponsalidade é de grande contribuição para formar a comunidade mundial, diante da unipluralidade de culturas e formas de viver.

O amor é o elo entre os povos, e haverá sempre um reconhecer que toda pessoa é à imagem e semelhança de Deus. $O$ amor é o 'local' onde se desenvolve a Nação dos filhos de Deus; isso possibilita a compreensão de que "todos os membros serão sujeitos conscientes dos próprios deveres e dos próprios direitos, e trabalharão em plano de igualdade, pela consecução do bem comum universal" (MM 173).

Desmistifica-se o chamado/mandado a todos os humanos de boa vontade, onde é de se verificar que "à questão da verdade e do sentido do viver social, com efeito, o homem não se pode furtar, pois a sociedade não é uma realidade estranha ao seu mesmo existir" (CDSI 163), e neste sentido se conclama todos, de modo que "Se é verdade que o mundo sofre por falta de convicções, nós convocamos os pensadores e os sábios, católicos, cristãos, os que honram a Deus, os que estão sedentos de absoluto, de justiça e de verdade" (PP 85).

É pela palavra, ciência, presença e potência humana, que se realiza a práxis de vida e vivência de cada pessoa, na comunicação efetiva entre os povos no mundo se poderá celebrar em comunhão, a unipluralidade e reciprocidade das culturas que emanam da vontade do Criador. Como isso, também é possível aprender as manifestações da vontade de Deus que se realiza na vida e vivência de cada povo.

Todas as vezes que o humano se idólatra por suas obras, também por sua cultura, torna-se implícito a "Torre de Babel" (cf. Gn 11,1-9), a tal ponto que, "A sociedade humana não estará bem constituída nem será fecunda a não ser que lhe presida uma autoridade legítima que salvaguarde as instituições e dedique o necessário trabalho e esforço ao bem comum" (PT 46).

\section{O planejamento é um exercício de Amor}

A capacidade de administrar e cocriar os mistérios de Deus estão para a essência administrativa, que habita o íntimo humano. Toda pessoa é partícipe da obra de Deus, administrando os subsídios, as necessidades, e as possibilidades. Nesse sentido, o ser humano em seu ambiente de vida e vivência se apresenta enquanto um ser em desenvolvimento.

A associação e interrelação entre Teologia e Administração podem explicitar-se diante da importância da esponsalidade com o Criador, isso porque, à medida que se administra a criação se responde à esponsalidade com Deus e, por isso, há práxis teológica, e à medida que se faz teologia compreende-se como administrar a Criação.

A esponsalidade possibilita o ser humano agir no espaço/tempo, na origem de eternidade que há em si, e o possibilita compreender o tempo na história da criação. As gerações são sempre 'diá-logos' com as construções humanas, a fim de buscar delas e nelas, as verdades que fundamentam sua continuidade. Esses elementos exigem planejamento, exercício à razão humana, no desafio de ser administrador e cocriador desse reino em desenvolvimento.

Neste sentido, há que se enfatizar que em "um mundo frágil, com um ser humano a quem Deus confia o cuidado do mesmo, interpela a nossa inteligência para reconhecer como deveremos orientar, cultivar e limitar o nosso poder" (LS 78), aqui novamente se explicita que se é o homo ad-minister, ad-minus. Os filhos são diá-logos profundos de nossas culturas, costumes, valores, com o próprio reino de Deus e, quando se coloca ao diálogo, é possível verificar o que há de proibido em cada fruto.

Há, então, o interesse de ausentar-se de ideologia reducionista que visa qualificar os frutos como proibidos, para que a ciência, a potência, e a presença humana possam compreender o que há de proibido em cada fruto. Assim, todo pai/mãe apresenta o Jardim ao filho/a e ensina-lhe o que há de proibido em cada fruto. 
Uma informação de suma importância, e que "sempre que a força do nosso argumento for a autoridade, em vez do encantamento, teremos um indicativo de que estamos insistindo demais exatamente naquilo que precisa ser abandonado" (SANCHES, 2013, p. 21). O ato administrativo é atitude consciente, que deseja cocriar e administrar a criação de Deus, e nesse sentido, "as pessoas exercem o domínio divinamente legitimado apenas como Imagem de Deus" (MOLTMANN, 1993, p. 324).

Implica dizer, reconhecer, que enquanto criatura, em esponsalidade, se é capacitado a participar do ato criador de Deus, aderindo ao projeto de amor e comunhão. A atitude humana no espaço/tempo se faz acontecer na comunhão dos participes da obra de Deus. E, então, a esponsalidade propulsa a essência administrativa, que é práxis, aqui como "semelhança de Deus é oferta e tarefa, indicativo e imperativo. Ela é tarefa e esperança, imperativo e promessa" (MOLTMANN, 1993, p. 327).

Ao observar a pessoa no ato administrativo e cocriador, que se faz em esponsalidade, enfatiza-se que "como imagem terrestre de Deus, elas refletem a glória do criador. Elas não são apenas pessoas encarregadas de algo, mas são também formas de Deus aparecer em sua criação" (MOLTMANN, 1993, p. 328), então é na atitude de cada pessoa que se faz perceber o agir de Deus na criação.

Diante da árvore da vida o ser humano é capaz de observar o que há de proibido no Jardim, isso implica dizer que o humano exaure sua solidão original à medida que, em esponsalidade, se permite a práxis da essência administrativa. Mediante o conhecimento, o ser humano vai, aos poucos, aprendendo a cocriar e a administrar o reino de Deus. A própria morte oferece a possibilidade de adentrar o movimento da criação, onde o mal não é uma possibilidade, e que cada vida será desvestida do que foi auferido pelo mal.

A direção de nossa peregrinação alcançará sua consumação em um novo estado ontológico em que a identidade não mais estará vinculada a contingência. Os fiéis de Deus encontrar-se-ão claramente além do Éden, pois serão 'incapazes de pecar' (SPONHEIM, 1987, p. 454).

Negar o princípio é negar a criação, e, a si mesmo, portanto, quem nega a práxis de si ao mundo, nega a vontade de Deus. $O$ humano é o húmus da terra, edificado por Deus no chamado a $\mathrm{Si}$ e no mandado de $\mathrm{Si}$, por isso cada pessoa, "no dar do mundo, quando o eu é criado ele é exigido, para o bem da humanidade" (SPONHEIM, 1987, p. 251).

A herança que se deve possibilitar é a consciência de um reino/humanidade e a função de cada pessoa conforme seus dons, mesmo porque "e pela realidade triúna do que quer que Deus seja, a Palavra que Ele é, é um diálogo, não uma palestra" (JENSON, 1987, p. 190). Oferecer Vida em abundância é fazer com que a morte encontre o ser humano vivo, sedento de vida, e não declinado de sua missão de ser cocriador e administrador do reino, esperançado por Deus à vida humana.

O ser humano é chamado a fazer junto, a edificar o reino; toda pessoa é ad-ministro de Deus que se coloca junto e em comunhão para realizar o reino esperançado à vida humana. “Com efeito, a verdade é 'lógos' que cria 'diá-logos' e, consequentemente, comunicação e comunhão" (CiV 4). O diálogo com Deus se estabelece por intermédio de sua criação; realizar a vontade de Deus é aceitar ser da família, filhos e povo de Deus.

\section{Administrar é expressar comunhão}

Deus possibilita, diante da fragilidade da vida humana, um reino em desenvolvimento, fomentando as possibilidades e necessidades. Quando se diz da ciência do bem e do mal, não se deseja classificar a ciência, mas enfatizar que diante da ciência, da pesquisa e do 
desenvolvimento, o ser humano está apto a tomar decisões e a indicar o que há de proibido em cada descoberta, bem como a compreender o que há de proibido no caminho/método para se chegar ao conhecimento.

Dessa forma, a comunhão e o trabalho são fontes de sustento da vida humana, que subsiste na economicidade, na sociabilidade e na parentalidade, ou seja, no dom de compreender as necessidades, as possibilidades e os subsídios necessários para edificar a vida humana em determinado espaço no tempo, por isso,

Não é justo que o indivíduo ou a família sejam absorvidos pelo Estado, mas é justo, pelo contrário, que aquele e esta tenham a faculdade de proceder com liberdade, contando que não atentem contra o bem geral, e não prejudiquem ninguém (RN 19).

Em se tratando de parentalidade, de economicidade e de sociabilidade, torna-se possível enfatizar que a separação do ambiente de trabalho da família e seu sentido humanizador embaraçam as formas de relacionamento parental com a família humana; desfazendo-se, então, a comunhão de vida humana. $\bigcirc$ trabalho, quando desassociado da práxis de vida e vivência familiar, acaba por deixar o humano carente de relação, e consequentemente desenvolve a egolatria, o nacionalismo, e se finda em um individualismo hostil ao reino.

Quando se desvinculam as dimensões de economicidade, de sociabilidade e de parentalidade da família humana, deturpa-se o sentido de humanidade. $O$ desenvolvimento acontece em virtude da construção de sistemas estatais de controle, "Torre de Babel" (cf. Gn 11,1-9), findando-se em familismo, em nacionalismos e em e ideologias protecionistareducionistas, e assim,

O irmão mata o irmão. Como naquele primeiro fratricídio, também em cada homicídio é violado o parentesco 'espiritual' que congrega os homens numa única grande família, sendo todos participantes do mesmo bem fundamental: a igual dignidade pessoal. (EV 8).

O Humano é ser com o outro, isso se explica na saudação amorosa de Adão a Eva, essa sim é "ossos dos meus ossos e carne da minha carne" (cf Gn 2,23), é um reconhecer-se. Não é um ser dualista, mas um ser social, que vive com o outro e no outro a própria vida. Diante de cada ser humano, a criação pode ser observada por si mesma, todavia, enquanto essência administrativa, o humano se permite observar, mediante atitudes de amor e desenvolvimento. Assim cada nova possibilidade, se revela enquanto atitude de quem é à imagem e semelhança de Deus.

Deus cria do nada/ex-nihilo, bem como exerce a capacidade de transformação, administração e cocriação, no zelo permanente e amoroso da criação. O próprio perdão é cocriação, é administração amorosa de Deus. Neste sentido de esponsalidade é práxis de vida e vivência humana, é preciso firmar que "Se Cristo é chamado de Palavra ou Logos, isto não quer dizer que Ele seja o caso lúcido de ideais gerais, mas que ele é a auto-representada parábola humana da divindade" (AUSTIN FARRER apud SPONHEIM, 1987, p. 234).

O ser humano é um ser social, isso implica dizer que a "sociabilidade constitutiva do ser humano, que tem o seu protótipo na relação originária entre o homem e a mulher, 'união esta que foi a primeira expressão da comunhão de pessoas"' (CDSI 37). A dimensão parental está para que, diante da sociabilidade, o humano perceba-se na unidualidade do casal, responsável pela continuidade da existência da vida humana. Se no encontro do casal é possibilitada uma nova vida, o encontro com o próximo edifica a vivência humana no reino. 
Por intermédio do vínculo unitivo e procriativo, os cônjuges "expressam reciprocamente o seu amor pessoal na 'linguagem do corpo', que comporta claramente e, ao mesmo tempo, 'significados esponsais' e parentais" (DV 4b), e torna enfático que a parentalidade não deve se fechar em si mesma, mas ser um serviço à obra de Deus.

A economicidade propulsa o ser humano a administrar "cultivar e guardar a criação" (Gn 2,15), zelando pelos recursos, com os quais precisa conduzir-se, conduzindo a obra de Deus, e "descobrindo, em crescente progressão, 'a inexplorável riqueza de Cristo' (Ef 3, 8), na criação, o trabalho humano se transforma num serviço prestado à grandeza de Deus" (CDSI 262).

\section{Considerações}

Não se pode limitar a razão humana, em virtude da contingência do ato da pessoa, o ser humano movimenta-se no sentido de possibilitar a autonomia da obra, para que possa, assim, administrá-la e desenvolver a vida humana no Jardim. Neste sentido, se apresenta o ato do ser humano que é, à imagem e semelhança de Deus, fomentando que este ato é de elevado valor e, se torna o ato administrativo e cocriador de Deus.

A capacidade de administrar: planejar, decidir, prever, realizar e controlar, evidencia a pessoa que, mediante, o passado, o presente e a expectação planeja o futuro. Esse futuro, se realiza em esponsalidade com o Criador, para que assim se perceba que, entre a potencialidade da razão e a contingência do ato humano é, necessário o ser humano criar e desenvolver a globalização, a tecnologia e toda ciência que se fizer necessária, isso não é tornar esses valores absolutos, mas todo conhecimento, des-envolvimento, ciência e tecnologia deve ser pensado em esponsalidade com o Criador.

A esponsalidade possibilita ao ser humano compreender, mediante a Essência Administrativa, seu ser livre e finito e com isso, perceber o que há de proibido em cada fruto. A pessoa é plenamente capaz de perceber o que há de bom, de belo e de verdadeiro nas coisas que desenvolve, por isso, a ciência é boa, o uso que o ser humano faz dela - ciência - é o que pode ocasionar a destruição, demolição e demonização do reino.

Compreender o ser humano que é, à imagem e semelhança de Deus, é perceber a própria capacidade humana de servir à obra de Deus, por isso a essência administrativa é o dom primeiro, pelo qual a pessoa é capacitada no chamado/mandato a administrar os mistérios de amor. Administrar a obra de Deus é expressão comunhão é, possibilitar que onde houver desiquilíbrios o ser humano estará ali para decidir corretamente o que fazer, para que o Jardim continue sempre fecundo e prolifero ao amor.

Em se tratando de parentalidade: possibilitar que o Jardim continue fecundo e prolifero é zelar da vida humana, planejar os filhos e, as relações destes com a vida humana. Neste sentido, cada filho precisa ser pensado sob as perspectivas de economicidade, parentalidade e sociabilidade e, deste modo, serem capacitado ao livre-arbítrio, isto é, serem capazes de discernir entre o bem e o mal que pode praticar.

\section{Referências}

BENTO XVI. Caritas In Veritate. Roma: Libreria Editrice Vaticana, 2009. Disponível em http:/ / w2.vatican.va / content / benedictxvi/pt/ encyclicals/documents/hf_benxvi_enc_20090629_caritas-in-veritate.html Acesso em: 29 set. 2017.

BíBLIA. Português. Bíblia de Jerusalém. Nova edição revisada e ampliada. São Paulo: Paulus, $8^{\mathrm{a}}$ impressão, 2012. 
BRAATEN, Carl E. A pessoa de Jesus Cristo. In: BRAATEN, CARL E.; JENSON, ROBERT W. (editores). Dogmática Cristã. São Leopoldo, RS: Sinodal, 1987. p. 455-551.

BRUNER, J. Atos de significação. 2. ed. Trad. Sandra Costa. São Paulo: Artmed, 2002.

CLANDININ, D. Jean. CONELLY, F. Michael. Pesquisa narrativa: experiências e história na pesquisa qualitativa. Tradução: Grupo de Pesquisa Narrativa e Educação de Professores ILEEL/UFU. Uberlândia: EDUFU, 2011.

FRANCISCO. Laudato Si'. Roma: Libreria Editrice Vaticana, 2015. Disponível em: http:/ / w2.vatican.va/ content/ francesco/pt/ encyclicals / documents/ papafrancesco_20150524_enciclica-laudato-si.html Acesso em: 29 set. 2017.

HEFNER, Philip J. A Criação. In: BRAATEN, CARL E.; JENSON, ROBERT W. (editores). Dogmática Cristã. São Leopoldo, RS: Sinodal, 1987. p. 273-358.

JENSON, Robert W. O Deus Triúno. In: BRAATEN, CARL E.; JENSON, ROBERT W. (editores). Dogmática Cristã. São Leopoldo, RS: Sinodal, 1987. p. 95-202.

JOÃO PAULO II. Compêndio da Doutrina Social da Igreja. Roma: Libreria Editrice Vaticana, 2004. Disponível em:

<http:/ / www.vatican.va/ roman_curia/ pontifical_councils/ justpeace/documents/rc_pc_justpea ce_doc_20060526_compendio-dott-soc_po.html> Acesso em: 29 set. 2017.

JOÃO PAULO II. Donum Vitae. Roma: Libreria Editrice Vaticana, 1987. Disponível em:<http:/ / www.vatican.va/roman_curia/ congregations/ cfaith/documents/rc_con_cfaith_doc _19870222_respect-for-human-life_po.html> Acesso em: 29 set. 2017.

JOÃO PAULO II. Evangelium vitae. Roma: Libreria Editrice Vaticana, 1995. Disponível em: $<$ http:/ / w2.vatican.va/ content/paul-vi/ pt/ encyclicals/documents/hf_pvi_enc_25071968_humanae-vitae.html> Acesso em: 29 set. 2017.

JOÃO XXIII. Mater et magistra. Roma: Libreria Editrice Vaticana, 1961. Disponível em: <http:/ / w2.vatican.va/ content/john-xxiii/pt/ encyclicals/documents/hf_jxxiii_enc_15051961_mater.html> Acesso em: 29 set. 2017.

JOÃO XXIII. Pacem in Terris. Roma: Libreria Editrice Vaticana, 1963. Disponível em: <http:/ / w2.vatican.va/ content/john-xxiii/pt/ encyclicals/documents/hf_jxxiii_enc_11041963_pacem.html> Acesso em: 29 set. 2017.

LEÃO XIII. Rerum Novarum. Roma: Libreria Editrice Vaticana, 1891. Disponível em: <http:/ / w2.vatican.va/ content/ leo-xiii/ pt/ encyclicals/documents/hf_lxiii_enc_15051891_rerum-novarum.html> Acesso em: 29 set. 2017.

PAULO VI. Gaudium et Spes. Roma: Libreria Editrice Vaticana, 1965. Disponível em: $<$ http:/ / www.vatican.va/archive/ hist_councils/ii_vatican_council/documents/vatii_const_19651207_gaudium-et-spes_po.html> Acesso em: 29 set. 2017. 
PAULO VI. Populorum Progressio. Roma: Libreria Editrice Vaticana, 1967. Disponível em: <http:/ / w2.vatican.va/ content/paul-vi/pt/ encyclicals/ documents/hf_pvi_enc_26031967_populorum.html> Acesso em: 29 set. 2017.

RAHNER, Karl. Teologia e Antropologia. São Paulo, SP: Edições Paulinas, 1969.

SANCHES, Mário Antônio. Reprodução Assistida e Bioética - Metaparentalidade. 1. ed. São Paulo: Ave Maria, 2013. v. 1. 218p.

SPONHEIM, Paul R. O conhecimento de Deus. In: BRAATEN, CARL E.; JENSON, ROBERT W. (editores). Dogmática Cristã. São Leopoldo, RS: Sinodal, 1987. p. 203-272.

SPONHEIM, Paul R. O pecado e o mal. In: BRAATEN, CARL E.; JENSON, ROBERT W. (editores). Dogmática Cristã. São Leopoldo, RS: Sinodal, 1987. p. 359-454. 